\title{
Efficacy of platelet-rich plasma injection in comparison to physical therapy for treatment of chronic partial supraspinatus
} tear

\author{
Sarah Saad Mohamed Ahmed Serya ${ }^{1}$, Nanis Onsy Neseem ${ }^{1}$, Reham M. Shaat ${ }^{1 *}$, Khaled Nour.A. ${ }^{2}$ and
} Mohammad K. Senna ${ }^{1}$

\begin{abstract}
Background: Supraspinatus tendon is a part of the rotator cuff of the shoulder, partial or full-thickness tear can affect the tendon secondary to trauma or repeated microtrauma. The aim of the present study is to evaluate the efficacy of platelet-rich plasma (PRP) injection in comparison to physical therapy for treatment of chronic partial supraspinatus tears.

Results: At the beginning of the study, there were no significant differences between both groups in all parameters: (a) PRP injection had significantly improved the visual analog scale (VAS), disabilities of arm, shoulder and hand scale (DASH) and shoulder range of motion (ROM) but not size of tear at 6 and 12 weeks post-injection in comparison to baseline recordings; (b) physical therapy had significantly improved VAS, DASH but not shoulder ROM nor size of tear at 6 and 12 weeks post-injection in comparison to baseline recordings; and (c) PRP injection was superior to physical therapy in the improvement of VAS, shoulder ROM, and DASH score.
\end{abstract}

Conclusion: The US-guided PRP injection is superior to physical therapy in improving pain, ROM, and function in treatment of partial thickness tear of supraspinatus tendon.

Keywords: Platelet-rich plasma, Supraspinatus tear, Physical therapy

\section{Background}

Prevalence of shoulder pain ranges between $16 \%$ and $26 \%$ of the general population; it is the third most common cause of musculoskeletal complaint, and approximately $1 \%$ of adults have new shoulder pain annually [1]. Rotator cuff tears are among the most common causes of chronic shoulder pain and disability [2], with the supraspinatus partial thickness tendon tears constitute $>50 \%$ of cases presenting with shoulder pain [3].

\footnotetext{
*Correspondence: rehamshaat@mans.edu.eg; reham1975@yahoo.com; rehamshaat@gmail.com

${ }^{1}$ Faculty of Medicine, Department of Rheumatology and Rehabilitation, Mansoura University, Mansoura City, Egypt

Full list of author information is available at the end of the article
}

Non-operative treatment options for supraspinatus tears include analgesics, local anesthetic, steroid injections, and physical therapy. Surgical interventions include repairs of torn and degenerate tears. Surgical repair which frequently fails due to many factors [4].

No therapy has been shown to uniformly improve clinical, functional, and radiological outcomes of rotator cuff tear (RCT), and no therapy has specifically targeted the underlying degenerative pathology of RCT [5].

Currently, in regenerative medicine, there are two new therapies that can repair and restore the damaged tissues, namely platelet-rich plasma (PRP) and stem cellbased therapies [6].

Platelets are rich in growth factors and play a crucial role by forming blood clots during injury. Platelets are

\section{Springer Open}

(ㅇ The Author(s). 2021 Open Access This article is licensed under a Creative Commons Attribution 4.0 International License, which permits use, sharing, adaptation, distribution and reproduction in any medium or format, as long as you give appropriate credit to the original author(s) and the source, provide a link to the Creative Commons licence, and indicate if changes were made. The images or other third party material in this article are included in the article's Creative Commons licence, unless indicated otherwise in a credit line to the material. If material is not included in the article's Creative Commons licence and your intended use is not permitted by statutory regulation or exceeds the permitted use, you will need to obtain permission directly from the copyright holder. To view a copy of this licence, visit http://creativecommons.org/licenses/by/4.0/. 
the frontline healing response to injuries as they are rich in granules that contain abundance of enzymes and growth factors that promote tissue repair and, hence, wound healing of damaged tissues depends on the platelet concentrations. PRP acts by inducing cells that can heal on their own or can augment the healing process leading to resolution of damaged tissues. One of the widely used applications of PRP is in the regeneration and reconstruction of skeletal and connective tissues in the periodontal and maxillofacial diseases and in sportsrelated injuries [7].

The principle idea of PRP is to increase the concentration of platelets; this increases growth factors and potentiates healing. PRP has an advantage over many of the tissue engineering products is that it is autologous [8].

Tendons generally have a poor blood supply and the torn or degenerated tissues are not able to receive the nutrients needed to stimulate repair and therefore, tendons have limited regeneration ability [5]. PRP injection to the injured site provides it with healing growth factors that are difficult to reach due to poor blood supply [9].

\section{Aim of the work}

The aim of the present study is to evaluate the efficacy of PRP injection in comparison to physical therapy for treatment of chronic partial supraspinatus tears.

\section{Methods}

Fifty-five consecutive patients with chronic partial supraspinatus tears were recruited from Rheumatology and Rehabilitation outpatient clinic xxxx University Hospital. From the initial 55 participants invited to participate, 12 participants were excluded from the study based on the exclusion criteria leaving only 43 patients to participate in the study, and 2 patients lost from group 1 and 1 from group 2 during follow-up. Finally, the data of 40 patients were analyzed. The institutional research board of Faculty of Medicine, Mansoura University, approved this study (code:. MS/17.08.79 The trial was conducted according to the Declaration of Helsinki's principles, a written informed consent was taken from all patients.

\section{Inclusion criteria}

Patients with chronic supraspinatus tear were diagnosed by clinical examination and musculoskeletal ultrasound.

\section{Exclusion criteria}

Patients with any of the following were excluded from the study:

Age $>80$ years, complete supraspinatus tears, other rotator cuff lesions with/without supra-pinatus tears, diabetes, autoimmune diseases, hematological diseases (coagulopathy), anemia, thrombocytopenia, using of anticoagulants, and local steroid injection in the past 6 weeks,

\section{Data collection}

All patients subjected to full history-taking, including demographic data, dominant hand, any systemic disease, e.g., diabetes, cardiac diseases, gall bladder diseases, and autoimmune diseases, previous significant trauma or surgery to the shoulder, and previous steroid injection to the shoulder.

\section{Clinical examination}

All patients were subjected to history-taking, general examination, musculoskeletal examination, with stress on shoulder, cervical spine, and neurological examination to reveal possibility of referred pain.

\section{Ultrasound examination}

For examination of supraspinatus, patient should be in Crass position. The patient is seated, and the shoulder is extended, adducted, and internally rotated with the elbow flexed, the palm facing out, and the fingers pointing toward the contralateral scapula. Internal rotation allows the supraspinatus to become an anterior structure, and extension draws the supraspinatus anteriorly from beneath the acromion, allowing the maximal length of tendon to be visualized [10].

Scanning was performed by Siemens Acuson P300 machine, with linear probe frequency $13 \mathrm{MHz}$. Partialthickness tears manifest as focal, well-defined hypoechoic, or anechoic defects in the tendon but involve only the bursal or articular surface, and tendon should be visualized in two orthogonal imaging planes to confirm the finding [11]. US evaluation of other rotator cuff tendons was also performed.

\section{Sample size calculation}

Based on data from literature Ilhanli et al. [12], considering level of significance of $5 \%$, and power of study of $80 \%$, the sample size can be calculated using the following formula:

$\mathrm{n}=\left[\left(\mathrm{Z}_{\alpha / 2}+\mathrm{Z}_{\beta}\right)^{2}\left\{2(\mathrm{SD})^{2}\right\}\right] /(\text { mean difference between the two groups })^{2}$

where

$\mathrm{SD}=$ standard deviation

$Z_{\alpha / 2}$ : This depends on level of significance, for $5 \%$ this is 1.96

$Z_{\beta}$ : This depends on power, for $80 \%$ this is 0.84

Therefore,

$$
\mathrm{n}=\left[(1.96+0.84)^{2} \times\left\{2(14.22)^{2}\right\}\right] /(12.6)=19.97
$$

Based on the above formula, the sample size required per group is 20 patients. 


\section{Randomization}

Eligible patients $(n=43)$ were randomly allocated into the two treatment groups by means of block randomization (size of block $=4$, with size of last block $=2$ ), by the use of sealed envelope. Patients were blind to type of treatment. After inclusion of a patient, a physiatrist drew an envelope and opened it (Fig. 1).

\section{Preparation of PRP \\ PRP preparation}

Sixteen milliliters of blood was obtained from each patient using special PRP kits (GD medical pharma, Dutch company). Samples were collected on citrated tubes with a mixing ratio of 9:1 by volume. Tubes underwent 1st centrifugation at speed of $3000 \mathrm{rpm}$ (704 g) for $3 \mathrm{~min}$ (to separate red blood cells from plasma). Plasma was then removed by syringe and then placed into another sterile tube with no anti-coagulant and then underwent 2nd centrifugation at speed of $4000 \mathrm{rpm}$ (1252 g) for 15 min. The supernatant platelet-poor plasma was then removed leaving $2 \mathrm{ml}$ of PRP pellets in the sediment and suspended the PRP pellets by gentle shaking of the tube. PRP is activated by adding $200 \mu \mathrm{l}$ of 0.025 calcium chloride [13].

\section{Intervention}

\section{PRP-injection group}

PRP-injection group (PRPinj-G) contained 22 patients. Patients in this group received three US-guided PRP injections with 1 week interval. The injections were in the supraspinatus tendon and it was intra-lesional.

For injecting PRP, the patient sat with hand placed behind the buttock with the elbow pointed posteriorly. The site of injection was disinfected under aseptic precautions. Real-time US guidance was used during the injections. First, $1 \mathrm{~mL}$ of $1 \%$ lidocaine was administered; then, the solution in covered syringes using a 20-gauge needle.

\section{Post-injection care}

Patients were instructed to rest the shoulder for next 2 days. Acetaminophen and cold therapy were allowed for pain control.

Appreciating the role of exercise for patients with partial supraspinatus tears, patients were instructed afterwards for a home exercise program and were followed for proper prescription and advancement of it. Home exercise started 2 weeks after receiving the 3 injections for fear of disruption of any healing process that might be taking place. The program included: the pendulum exercise, wall crawl exercises in forward flexion and in abduction, standing forward flexion and abduction exercises using an exercise bar and horizontal closed chain exercises. Exercise was prescribed in 3 sets of 10 repetitions twice per day and it was performed and progressed as tolerated. One month after injection, patients started strengthening exercise.

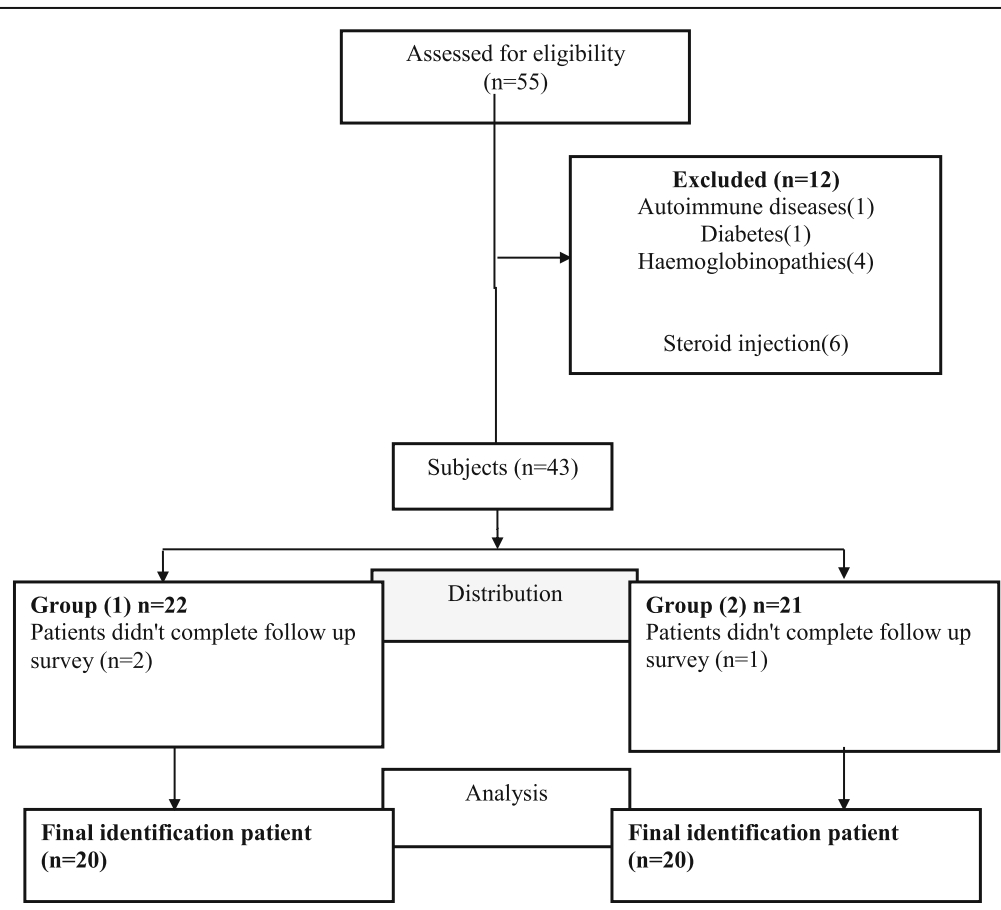

Fig. 1 Subjects flow diagram 


\section{Physical therapy group}

Physical therapy group (PhT-G) contained 21 patients. Patients in this group received laser therapy (Enraf Nonius, frequency $10,000 \mathrm{~Hz}$, for $10 \mathrm{~min}$ ), US therapy in continuous mode (Siemens, $1.5 \mathrm{~W} / \mathrm{cm}^{2}$, for $10 \mathrm{~min}$ ), ROM, stretch excercises, strengthening exercises 10 repeats, for 3 weeks, and 5 sessions a week. Afterwards, patients in this group were instructed to perform the same home exercise program as in the PRP-injection group. The addition of laser therapy to ultrasound has been reported to achieve better results in shoulder tendinitis than using the ultrasound therapy without laser [14].

\section{Assessment of outcome measures}

\section{Primary outcome measure}

1. Pain intensity-visual analog scale (VAS) was used in patients to measure pain intensity. The VAS-pain score is composed of a continuous horizontal line. $(0$ score $=$ no pain $)$ at one end and $(10$ score $=$ worst imaginable pain) [15].

2. Active shoulder range of motion measurement using goniometer [16].

\section{Secondary outcome measure}

1. Disability was measured using disabilities of arm, shoulder and hand (DASH) scale. The DASH is a self-report instrument that was designed to assess outcomes among patient groups with musculoskeletal disorders. Patients choose scores on a scale from 1 to 5 for 30 items relating to functional activities and symptoms. The raw score is then transformed from 0 to 100 scale, whereby 0 reflects minimum and 100 maximum disability [17].

2. US assessment of the size of tear-the size of tear was measured in millimeter [18].

Pain intensity, active ROM, and disability were assessed at baseline, at 6 , and at 12 weeks while the size of tear was evaluated by US examination at baseline and at 12 weeks only.

One investigator was responsible for clinical examination and clinical scores, other investigator was responsible for ultrasound-guided injection, a radiologist doctor was responsible for us imaging assessment, and, all of them were blind to the type of therapy.

\section{Statistical analysis}

All statistical analyses were performed using SPSS for windows version 20.0 (SPSS, Chicago, IL). Continuous data were tested for normality of distribution prior to calculation. Normally distributed continuous were expressed in mean \pm standard deviation (SD).
Categorical data were expressed in number and percentage. The comparisons were determined using Student's $t$ test for two variables or one-way analysis of variance (ANOVA) test for comparison among than two variables with continuous data. Chi-square test was used for comparison of variables with categorical data. The size of tear measured by US were abnormally distributed and were expressed as median and interquartile range (IQR) and were compared between the two groups and within each group using the Mann-Whitney $U$ test. Statistical significance was set at $p \leq 0.05$.

\section{Results}

This study included 43 patients with chronic partial supraspinatus tear. Patients were randomized into two groups: the PRP inj-G and the PhT-G. The PRP inj-G included 22 patients. The PhT-G included 21 patients, 3 patients lost during follow-up, and statistical analysis was done on data from 40 patients. The two groups were matched regarding age, sex, and duration of complaint (Table 1).

VAS-pain score was significantly lower in PRP inj-G than PhT-G at 6 and 12 weeks post-intervention ( $p=$ 0.034 and $p=0.004$, respectively) (Table 2 ).

The difference of the DASH score between the two treatment groups is shown in (Table 3), at 6 and 12 weeks post-intervention evaluations, and PRPinj-G had significantly lower DASH score than PhT-G ( $p=0.031$ and $p=0.029$, respectively).

Range of active shoulder abduction was significantly better in PRP inj-G than PhT-G at 12 weeks postintervention $(p=0.040)$. Shoulder active flexion was significantly better in PRP inj-G than in PhT-G at 6 weeks and 12 weeks post-intervention $(p=0.043$ and $p=$ 0.032 , respectively). Active shoulder extension was better in PRP inj-G than in the PhT-G at 6 weeks postintervention $(p=0.014)$ and at 12 weeks postintervention $(p=0.009)$. Range of active shoulder internal rotation was statistically better in PRP inj-G than in the PhT-G at 6 weeks $(p=0.043)$ and at 12 weeks post-intervention $(p=0.041)$. Range of shoulder active external rotation was significantly better in PRP inj-G than in PhT-G at $6(p=0.041)$ and 12 weeks postintervention $(p=0.039)$ (Table 4).

As shown in Table 5, the tear size did not differ significantly between the two groups at the end of the study (Fig. 2).

\section{Complications}

Regarding the adverse effects of PRP injection, three patients experienced post-injection pain, which was mainly treated with ice packing. One patient had post-injection 
Table 1 Comparison of the age, sex, duration of complaint, side of affected shoulder, and site of tear between the PRPinj-G and PhT-G

\begin{tabular}{|c|c|c|c|c|}
\hline & \multirow{2}{*}{$\begin{array}{l}\text { PRPinj-G } \\
\text { Mean } \pm \text { SD }\end{array}$} & \multirow{2}{*}{$\begin{array}{l}\text { PhT-G } \\
\text { Mean } \pm \text { SD }\end{array}$} & \multicolumn{2}{|c|}{ Student's $t$ test } \\
\hline & & & $\bar{t}$ & $P$ \\
\hline Age (years) & $52.0 \pm 9.9$ & $51.9 \pm 8.0$ & 0.035 & 0.972 \\
\hline \multicolumn{5}{|l|}{$\operatorname{Sex}(n, \%)$} \\
\hline Females & $9,45.0 \%$ & $8,40.0 \%$ & & \\
\hline Males & $11,55.0 \%$ & $12,60.0 \%$ & $0.102^{\mathrm{a}}$ & 0.749 \\
\hline Duration of complaint (months) & $13.7 \pm 6.3$ & $13.2 \pm 6.0$ & 0.257 & 0.799 \\
\hline Right shoulder affected (n, \%) & $9,45.0 \%$ & $10,50.0 \%$ & $0.100^{a}$ & 0.752 \\
\hline \multicolumn{5}{|l|}{ Location of tear } \\
\hline Intra-tendinous tear & $12,60.0 \%$ & $14,70.0 \%$ & & \\
\hline Articular surface & $8,40.0 \%$ & $6,30.0 \%$ & $0.440^{\mathrm{a}}$ & 0.507 \\
\hline
\end{tabular}

${ }^{a} \times 2$ value chi-square test, $t$ Student's $t$ test, $S D$ standard deviation, $n$ number, PRPinj-G platelet-rich plasma injection group, PhT-G physical therapy group, $p$ level of significance, $p \leq 0.05$ is considered significant

dizziness which was not considered to be a specific adverse effect regarding PRP.

\section{Discussion}

Several studies had investigated the usefulness of PRP in treatment of RCT administered either as an adjuvant to surgical repair [19] or as a primary infiltration [20]; however, results remain inconclusive [21] making it difficult to conclude if PRP injections are an effective treatment for this population.

The main findings of this study are that (a) all outcome measures (i.e., VAS-pain, DASH score, and active ROM) were significantly better in PRPinj-G at 6 and 12 weeks post-intervention than in PhT-G; (b) VAS-pain and DASH scores were significantly improved in the two groups at 6 and 12 weeks post-intervention in comparison to baseline; however, the ROM was significantly improved in PRPinj-G (but not in PhT-G) at 6 and 12 weeks post-intervention in comparison to baseline; and (d) US examination revealed that the size of the tear did not differ significantly between the two groups at the

Table 2 Comparison of the VAS-pain score between the PRPinj$G$ and PhT-G at baseline and after 6 and 12 weeks postintervention

\begin{tabular}{lllll}
\hline & PRPinj-G & PhT-G & \multicolumn{2}{l}{ Students t test } \\
\cline { 4 - 5 } & Mean \pm SD & Mean \pm SD & $\boldsymbol{t}$ & $\boldsymbol{p}$ \\
\hline At baseline & $7.5 \pm 1.8$ & $7.9 \pm 1.5$ & 0.857 & 0.397 \\
6 weeks post-intervention & $4.8 \pm 2.2$ & $6.4 \pm 2.4$ & 3.149 & 0.034 \\
12 weeks post-intervention & $3.5 \pm 1.6$ & $5.6 \pm 2.6$ & 3.076 & 0.004 \\
Repeated measure ANOVA test & & & \\
F & 23.477 & 5.538 & & \\
P & $<0.001$ & 0.006 & & \\
\hline FANOVA test,
\end{tabular}

F ANOVA test, $t$ Student's $t$ test, SD standard deviation, VAS visual analog scale, $P R P i n j-G$ platelet-rich plasma injection group, $P h T-G$ physical therapy group, $p$ level of significance, $p \leq 0.05$ is considered significant end of the study, and the tear size did not show significant improvement at the 12 weeks evaluation compared to the baseline size in the two groups.

Our results go with the clinical trial of Scarpone et al. [22]. Patients in that clinical trial received single USguided injection of $3 \mathrm{~mL}$ of $1.0 \%$ xylocaine, after that 3.5 $\mathrm{mL}$ of PRP was injected at the lesion and the surrounding tendon tissues. The 18 patients, with 19 evaluated shoulders, reported improved VAS-pain score and functional outcomes at week 12 and at 1-year assessment. Interestingly, the largest improvement in shoulder ROM in that study was found in the external rotation.

With similarity to our results with PRP, Rha et al. [23] compared the effects of PRP injection with that of dry needling on pain and function in cases with rotator cuff lesion. The study reported that the clinical effect of PRP injection was superior to the dry needling at 6 weeks and 6 months evaluation after initial injection regarding shoulder pain, disability index, passive ROM, and physician rating scale.

Table 3 Comparison of the DASH score between the PRPinj-G and PhT-G at baseline and after 6 and 12 weeks postintervention

\begin{tabular}{lllll}
\hline & PRPinj-G & PhT-G & \multicolumn{2}{l}{ Student's $\boldsymbol{t}$ test } \\
\cline { 4 - 5 } & Mean \pm SD & Mean \pm SD & $\boldsymbol{t}$ & $\boldsymbol{p}$ \\
\hline At baseline & $46.6 \pm 13.4$ & $45.8 \pm 11.1$ & 0.206 & 0.838 \\
6 weeks post-intervention & $30.2 \pm 10.7$ & $39.2 \pm 12.6$ & 2.246 & 0.031 \\
12 weeks post-intervention & $27.1 \pm 13.7$ & $36.2 \pm 11.6$ & 2.267 & 0.029 \\
Repeated measure ANOVA test & & & \\
$\quad$ F & 13.676 & 3.474 & & \\
p & $<0.001$ & 0.038 & &
\end{tabular}

F ANOVA test, $t$ Student's $t$ test, SD standard deviation, DASH disability of arm, shoulder and hand, PRPinj-G platelet-rich plasma injection group, PhT-G physical therapy group, $p$ level of significance, $p \leq 0.05$ is considered significant 
Table 4 Comparison of the range of movement of shoulder between the PRPinj-G and PhT-G at baseline and after 6 and 12 weeks post-intervention

\begin{tabular}{|c|c|c|c|c|}
\hline & \multirow{2}{*}{$\begin{array}{l}\text { PRPinj-G } \\
\text { Mean } \pm \text { SD }\end{array}$} & \multirow{2}{*}{$\begin{array}{l}\text { PhT-G } \\
\text { Mean } \pm \text { SD }\end{array}$} & \multicolumn{2}{|c|}{ Student's $t$ test } \\
\hline & & & $t$ & $p$ \\
\hline \multicolumn{5}{|l|}{ Shoulder abduction } \\
\hline At baseline & $105.8 \pm 25.7$ & $106.8 \pm 26.9$ & 0.120 & 0.905 \\
\hline 6 weeks post-intervention & $117.8 \pm 36.7$ & $110.0 \pm 22.8$ & 0.802 & 0.427 \\
\hline 12 weeks post-intervention & $137.3 \pm 29.9$ & $118.8 \pm 25.0$ & 2.123 & 0.040 \\
\hline \multicolumn{5}{|l|}{ Repeated measure ANOVA test } \\
\hline$F$ & 5.227 & 1.240 & & \\
\hline$p$ & 0.005 & 0.297 & & \\
\hline \multicolumn{5}{|l|}{ Shoulder flexion } \\
\hline At baseline & $115.5 \pm 28.1$ & $116.5 \pm 27.8$ & 0.113 & 0.911 \\
\hline 6 weeks post-intervention & $134.8 \pm 19.0$ & $120.0 \pm 25.1$ & 2.093 & 0.043 \\
\hline 12 weeks post-intervention & $147.3 \pm 22.8$ & $126.3 \pm 35.6$ & 2.220 & 0.032 \\
\hline \multicolumn{5}{|l|}{ Repeated measure ANOVA test } \\
\hline$F$ & 9.219 & 0.554 & & \\
\hline$p$ & $<0.001$ & 0.578 & & \\
\hline \multicolumn{5}{|l|}{ Shoulder extension } \\
\hline At baseline & $51.0 \pm 8.3$ & $50.3 \pm 8.2$ & 0.268 & 0.790 \\
\hline 6 weeks post-intervention & $57.9 \pm 4.9$ & $52.8 \pm 7.3$ & 2.584 & 0.014 \\
\hline 12 weeks post-intervention & $58.0 \pm 4.4$ & $53.0 \pm 6.8$ & 2.768 & 0.009 \\
\hline \multicolumn{5}{|l|}{ Repeated measure ANOVA test } \\
\hline$F$ & 8.607 & 0.814 & & \\
\hline$p$ & $<0.001$ & 0.448 & & \\
\hline \multicolumn{5}{|l|}{ Shoulder internal rotation } \\
\hline At baseline & $66.3 \pm 16.8$ & $67.8 \pm 19.1$ & 0.264 & 0.793 \\
\hline 6 weeks post-intervention & $78.9 \pm 12.1$ & $71.3 \pm 10.8$ & 2.096 & 0.043 \\
\hline 12 weeks post-intervention & $81.8 \pm 12.5$ & $74.0 \pm 10.7$ & 2.120 & 0.041 \\
\hline \multicolumn{5}{|l|}{ Repeated measure ANOVA test } \\
\hline$F$ & 6.966 & 0.973 & & \\
\hline$p$ & 0.002 & 0.384 & & \\
\hline \multicolumn{5}{|l|}{ Shoulder external rotation } \\
\hline At baseline & $62.5 \pm 14.1$ & $65.8 \pm 16.0$ & 0.682 & 0.500 \\
\hline 6 weeks post-intervention & $73.9 \pm 9.8$ & $67.1 \pm 10.5$ & 2.117 & 0.041 \\
\hline 12 weeks post-intervention & $77.8 \pm 10.7$ & $70.2 \pm 11.8$ & 2.134 & 0.039 \\
\hline \multicolumn{5}{|l|}{ Repeated measure ANOVA test } \\
\hline$F$ & 9.265 & 0.607 & & \\
\hline$p$ & $<0.001$ & 0.549 & & \\
\hline
\end{tabular}

F ANOVA test, $t$ Student's $t$ test, SD standard deviation, PRPinj-G platelet-rich plasma injection group, PhT-G physical therapy group, $p$ level of significance, $p \leq 0.05$ is considered significant

Mautner et al. [24] conducted a retrospective, crosssectional survey with similar results to our results; 21 patients had supraspinatus partial tear who were refractory to conventional treatments and who received USguided PRP injections, and they reported that $75 \%$ of the patients showed decrease in VAS-pain score and, at follow-up, about $95 \%$ of patients reported no pain at rest while $68 \%$ reported no pain during activities.

Wesner et al. [25] revealed similar results to our study; the results showed that patients in PRP group reported 
Table 5 Comparison of the supraspinatus partial tear size between the PRPinj-G and PhT-G at baseline and after 6 and 12 weeks post-intervention

\begin{tabular}{llll}
\hline & $\begin{array}{l}\text { PRPinj-G } \\
\text { Median [IQR] }\end{array}$ & $\begin{array}{l}\text { PhT-G } \\
\text { Median [IQR] }\end{array}$ & $\begin{array}{l}\text { Mann-Whitney } \boldsymbol{U} \\
\text { test }(\boldsymbol{p} \text { value) }\end{array}$ \\
\hline $\begin{array}{l}\text { Longitudinal scanning } \\
\text { Baseline }\end{array}$ & $6.5[5.1]$ & $6.3[5.4]$ & 0.629 \\
12 weeks post-intervention & $6.2[3.6]$ & $6.1[4.0]$ & 0.338 \\
Mann-Whitney $U$ test $(p$ value) & 0.121 & 0.190 & \\
Transverse scanning & & $7.4[5.0]$ & 0.813 \\
Baseline & $7.3[5.2]$ & $7.0[4.7]$ & 0.333 \\
12 weeks post-intervention & $6.9[4.2]$ & 0.112 & \\
Mann-Whitney $U$ test $(p$ value) & 0.111 & & \\
\hline
\end{tabular}

$U$ Mann-Whitney $U$ test, $S D$ standard deviation, PRPinj-G platelet rich plasma injection group, PhT-G physical therapy group, IQR interquartile range, $p$ level of significance, $p \leq 0.05$ is considered significant

clinically significant improvements in pain, disability, and tendon pathology whereas those in placebo group did not.

The study of Tahririan et al. [26] was in agreement with our study; patients were enrolled to receive USguided PRP injection via posterior sub-acromial approach and revealed significant improvement of the pain and shoulder functional score at 3 months evaluation after injection.

Zafarani et al. [27] enrolled patients with PT-RCT for injection with autologous PRP preparation into subacromial bursa and intra-articular space. The study found that PRP injection had all outcomes including improved pain, function, and DASH scores as well as shoulder ROM which were similar to our results.

Barreto et al. [28] designed a research aimed to evaluate efficacy of PRP injection compared to subacromial corticosteroid injection in the treatment of rotator cuff partial tears. Patients in both groups reported a significant DASH scores improvement in comparison to the baseline, yet with no difference between the two groups at all evaluation steps, with difference to our results in superiority of PRP to improve pain, function, and ROM as their second group was different; it was corticosteroid injection.

These previous studies together with the findings of this study support the beneficial effects of the PRP injection as indicated by clinical improvement evidenced by improvement of the pain, functional scores, and the ROM of the shoulder in comparison to the baseline values of these parameters.

The beneficial effects of the PRP injections in tendinopathy were also supported by several studies that assessed the effect of PRP on the process of tendon healing; platelets are source of a lot of cytokines, chemokines, GFs, and many other mediators involved in tissue regeneration [29].

Basic science studies have consistently shown the beneficial effects of PRP on tendons including increased tendon cell proliferation, increased expression of
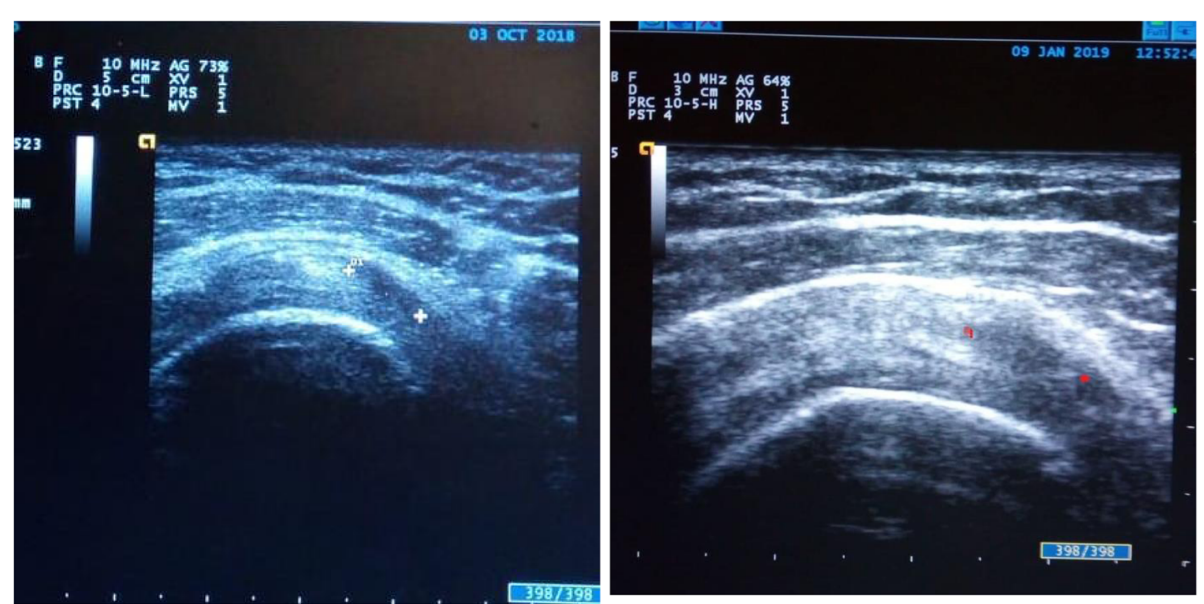

Fig. 2 US imaging for transverse axis US showing partial supraspinatus tear in left shoulder of a 57-year-old male patient a before PRP injection (tear size $=9.3 \mathrm{~mm}$ ) and $\mathbf{b} 12$ weeks post-injection (tear size $=9.1 \mathrm{~mm}$ ) 
anabolic genes and proteins, and reduced tendon inflammation [30].

Ilhanli et al. [12] reported significant improvement in ROM, pain, and DASH scores at 1-month and 1-year evaluations after the end of the treatment in the two groups. Moreover, at the all evaluation steps, improvement of VAS-pain and DASH scores was significantly better in PRP injection group than in PhT-G which also is in agreement with our results. However, in contrast to our results, Ilhanli et al. found that at all evaluation steps, improvement of ROM was significantly better in the PhT-G than PRP injection group regarding flexion, extension, abduction, and external rotation, but PRP group had significantly better internal rotation than PhT-G at end of study. The discrepancy between the findings of our study and the study of Ilhanli et al. can be explained by the fact that the two groups in that study were not matched at baseline regarding the ROM in the favor of PhT-G. Moreover, injections in the PRP group in Ilhanli et al. were intra-articular and not ultrasound guided, while in our study, the injections were ultrasound-guided intra-tendinous which ensured more accurate delivery of the PRP substance into the appropriate site of pathology.

In contrast to our findings, other studies did not support the clinical beneficial effect of PRP in supraspinatus partial thickness tear. In this context, Kesikburun et al. [20] revealed that patients in PRP group received an USguided $5.0 \mathrm{~mL}$ of PRP injection into the subacromial space while patients in the other group received same amount of saline solution. Despite that within each group, pain showed significant improvements at end of study in comparison to the baseline at all-time points; shoulder ROM and the functional score showed no significant differences between the groups or within each group at any assessment time point. In addition, the study found no significant differences between the groups in all outcome measures neither at 1-year followup nor at other assessment points; the difference to our results as regards the efficacy of PRP may be contributed to the use of single injection in this study which will not be effective.

In the randomized controlled trial of Kim et al. [18], change showed that the VAS-pain score and functional score differed significantly between the two treatment groups at 12 weeks but not at 3 weeks. On the other hand, the US examination revealed that the tear size was reduced at 3 weeks with the decrease being more evident at 3 months in the bone marrow aspirate concentration and PRP injection group but was not significantly different from that of the control group. The findings of that study support the findings of our study in that PRP injections did not significantly reduce the tear size despite the significant clinical improvement.
The inability to detect significant evidence of tendon healing by ultrasonography in our study can be attributed to the short follow-up period; the need for multiple PRP injections, the small sample size, or possibly the US lacks enough sensitivity to detect the histological improvement in tendons that had been reported in many in vitro and in vivo studies.

In a recent study by Christopher Centeno et al. [31], who studied the role of injectable regenerative therapies such as bone marrow concentrate (BMC) and plateletrich plasma (PRP), the findings suggest that ultrasoundguided BMC and platelet product injections are safe and useful alternatives to conservative exercise therapy of torn, non-retracted supraspinatus tendons, suggesting that adding bone marrow concentrate to PRP may be of benefit in reducing the size of the tear.

There are some limitations regarding the usefulness of PRP in the treatment of PT-RCT. The first limitation is the lack of standardization of PRP dosing, formulation, and concentration of platelets and GFs that comprise the PRP preparation. In addition, the advantage of including leukocytes in PRP preparation remains an issue of debate. Another point of limitation is the different PRP application techniques of among these differences render cross-study comparisons difficult to interpret. To further outline the effectiveness of PRP for treatment of PT-RCT, more double-blinded, randomized controlled trials with large sample sizes and optimized PRP preparations are warranted.

\section{Conclusion}

The US-guided PRP injection is superior to physical therapy in improving pain, ROM, and function in patients with chronic partial thickness tear of supraspinatus tendon.

\section{Abbreviations \\ BMC: Bone marrow concentrate; DASH: Disability of arm, shoulder and hand; GFs: Growth factors; Inj-G: Injection group; IQR: Interquartile range; L- \\ PRP: Leukocyte-platelet-rich plasma; MRI: Magnetic resonance imaging; NSAI Ds: Non-steroidal anti-inflammatory drugs; PRF: Platelet-rich fibrin; PRP: Platelet-rich plasma; PhT-G: Physical therapy group; PT-RCT: Partial rotator cuff tear; RCT: Rotator cuff tear; ROM: Range of motion; VAS: Visual analog scale; SD: Standard deviation; US: Ultrasound}

\section{Acknowledgements \\ All authors wish to express great appreciations for all cooperative patients included in this study.}

\section{Authors' contributions}

RS, SS, KA, NN, and MS were responsible for the idea, study design, patient selection, and examination. SS was responsible for assessment of clinical scores. RS was responsible for ultrasound-guided intervention. All authors were responsible for interpretation of statistical analysis and the results, writing, revising, and approval of the final submitted manuscript.

\section{Funding}

This study had no funding from any resource. 


\section{Availability of data and materials}

The datasets used and/or analyzed during the current study are available from the corresponding author on reasonable request.

\section{Ethics approval and consent to participate}

The present study was conducted in agreement with the guidelines of the Declaration of Helsinki. This study was approved by institutional research board of Faculty of Medicine, Mansoura University (code: MS/17.08.79) on 17 August 2018. A written informed consent was taken from all participants, according to ethical standards of institutional research board Mansoura University.

\section{Consent for publication}

Not applicable.

\section{Competing interests}

All authors declare that they have no competing interests.

\section{Author details}

'Faculty of Medicine, Department of Rheumatology and Rehabilitation, Mansoura University, Mansoura City, Egypt. ${ }^{2}$ Faculty of Medicine, Department of Orthopedic Surgery, Mansoura University, Mansoura City, Egypt.

\section{Received: 28 November 2020 Accepted: 8 January 2021}

Published online: 04 February 2021

\section{References}

1. Umer M, Qadir I, Azam M (2012) Subacromial impingement syndrome. Orthop Rev (Pavia) 4(2):e18 79-82

2. Fongemie AE, Buss DD, Rolnick SJ (1998) Management of shoulder impingement syndrome and rotator cuff tears. Am Fam Physician 57(4): 667-674

3. Kim HM, Dahiya N, Teefey SA, Middleton WD, Stobbs G, Steger-May K et al (2010) Location and initiation of degenerative rotator cuff tears: an analysis of three hundred and sixty shoulders. J Bone Joint Surg Am 92(5):10881096

4. Mei-Dan O, Carmont MR (2011) The role of platelet-rich plasma in rotator cuff repair. Sports Med Arthrosc Rev 19(3):244-250

5. Ho JO, Sawadkar P, Mudera V (2014) A review on the use of cell therapy in the treatment of tendon disease and injuries. J Tissue Eng 18(5):204-213

6. Lysaght MJ, Crager J (2009) Origins. Tissue EngPart A 15(7):1449-1450

7. Alsousou J, Ali A, Willett K, Harrison P (2013) The role of platelet-rich plasma in tissue regeneration. Platelets 24(3):173-182

8. Soomekh DJ (2011) Current concepts for the use of platelet-rich plasma in the foot and ankle. Clin Podiatr Med Surg 28(1):155-170

9. van Ark M, Zwerver J, van den Akker-Scheek I (2011) Injection treatments for patellar tendinopathy. Br J Sports Med 45(13):1068-1076

10. Ferri M, Finlay K, Popowich T, Stamp G, Schuringa P, Friedman L (2005) Sonography of full-thickness supraspinatus tears: comparison of patient positioning technique with surgical correlation. AJR Am J Roentgenol 184(1):180-184

11. Moosikasuwan JB, Miller TT, Burke BJ (2005) Rotator cuff tears: Clinical, radiographic, and US findings. Radiographics 25(6):1591-1607

12. IIhanli I, Guder N, Gul M (2015) Platelet-rich plasma treatment with physical therapy in chronic partial supraspinatus tears. Iran Red Crescent Med J 17(9): e23732

13. Dhurat R, Sukesh M (2014) Principles and methods of preparation of platelet-rich plasma: a review and author's perspective. J Cutan Aesthet Surg 7(4):189-197

14. Otadi K, Hadian MR, Olyaei G, Jalaie S (2012) The beneficial effects of adding low level laser to ultrasound and exercise in Iranian women with shoulder tendinitis. J Back Musculoskelet Rehabil 25(1):13-19

15. Jensen MP, Karoly P, Braver S (1986) The measurement of clinical pain intensity: a comparison of six methods. Pain 27(1):117-126

16. Clarkson HM (2013) Shoulder complex. Chap 3; musculoskeletal assessment. joint motion and muscle testing. $3^{\text {rd }}$ North American edition. Lippincott Williams \& Wilkins, United States, pp 82-93

17. Germann G, Wind G, Harth A (1999) The DASH (Disability of Arm-ShoulderHand) Questionnaire--a new instrument for evaluating upper extremity treatment outcome. Handchir Mikrochir Plast Chir 31(3):149-152
18. Kim SJ, Kim EK, Kim SJ, Song DH (2018) Effects of bone marrow aspirate concentrate and platelet-rich plasma on patients with partial tear of the rotator cuff tendon. J Orthop Surg Res 13(1):1

19. Saltzman BM, Jain A, Campbell KA, Mascarenhas R, Romeo AA, Verma NN et al (2016) Does the use of platelet-rich plasma at the time of surgery improve clinical outcomes in arthroscopic rotator cuff repair when compared with control cohorts? A systematic review of meta-analyses. Arthroscopy 32(5):906-918

20. Kesikburun S, Tan AK, Yilmaz B, Yaşar E, Yazicioğlu K (2013) Platelet-rich plasma injections in the treatment of chronic rotator cuff tendinopathy: a randomized controlled trial with 1-year follow-up. Am J Sports Med 41(11): 2609-2616

21. Filardo G, Di Matteo B, Kon E, Merli G, Marcacci M (2018) Platelet-rich plasma in tendon-related disorders: results and indications. Knee Surg Sports Traumatol Arthrosc 26(7):1984-1999

22. Scarpone M, Rabago D, Snell E, Demeo P, Ruppert K, Pritchard P et al (2013) Effectiveness of platelet-rich plasma injection for rotator cuff tendinopathy: a prospective open-label study. Glob Adv Health Med 2(2):26-31

23. Rha DW, Park GY, Kim YK, Kim MT, Lee SC (2013) Comparison of the therapeutic effects of ultrasound-guided platelet-rich plasma injection and dry needling in rotator cuff disease: a randomized controlled trial. Clin Rehabil 27(2):113-122

24. Mautner K, Colberg RE, Malanga G, Borg-Stein JP, Harmon KG, Dharamsi AS et al (2013) Outcomes after ultrasound-guided platelet-rich plasma injections for chronic tendinopathy: a multicenter, retrospective review. PM R 5(3):169-175

25. Wesner M, Defreitas T, Bredy H, Pothier L, Qin Z, McKillop AB et al (2016) A Pilot study evaluating the effectiveness of platelet-rich plasma therapy for treating degenerative tendinopathies: a randomized control trial with synchronous observational cohort. PLoS One 11(2):e0147842

26. Tahririan MA, Moezi M, Motififard M, Nemati M, Nemati A (2016) Ultrasound guided platelet-rich plasma injection for the treatment of rotator cuff tendinopathy. Adv Biomed Res 5:200

27. Zafarani Z, Mirzaee F, Guity M, Aslani H (2017) Clinical results of platelet-rich plasma for partial thickness rotator cuff tears: a case series. Arch Bone Jt Surg 5(5):328-331

28. Barreto RB, Azevedo AR, de Gois MC, de Menezes Freire MR, Silva DS, Cardoso JC (2019) Platelet-rich plasma and corticosteroids in the treatment of rotator cuff impingement syndrome: randomized clinical trial. Rev Bras Ortop Epub ahead of print

29. Mishra A, Woodall JJ, Vieira A (2009) Treatment of tendon and muscle using platelet-rich plasma. Clin Sports Med 28(1):113-125

30. Zhou Y, Wang JH (2016) PRP treatment efficacy for tendinopathy: a review of basic science studies. Biomed Res Int 2016:9103792. https://doi.org/10. $1155 / 2016 / 9103792$

31. Centeno C, Fausel Z, Stemper I, Azuike U, Dodson E (2020) A randomized controlled trial of the treatment of rotator cuff tears with bone marrow concentrate and platelet products compared to exercise therapy: a midterm analysis. Stem Cells Int 30:5962354

\section{Publisher's Note}

Springer Nature remains neutral with regard to jurisdictional claims in published maps and institutional affiliations.

\section{Submit your manuscript to a SpringerOpen ${ }^{\circ}$ journal and benefit from:}

- Convenient online submission

- Rigorous peer review

- Open access: articles freely available online

High visibility within the field

- Retaining the copyright to your article

Submit your next manuscript at $>$ springeropen.com 